\title{
Бедность российских профессионалов: распространенность, причины, тенденции
}

\author{
Н.Е. ТИХОНОВА*, Е.Д. СЛОБОДЕНЮК $* *$
}

\begin{abstract}
"Наталья Евгеньевна Тихонова - доктор социологических наук, профессор-исследователь, Национальный исследовательский университет «Высшая школа экономики»; главный научный сотрудник, Институт социологии ФНИСЦ РАН, Москва, Россия, ntihonova@hse.ru, https://orcid.org/0000-0002-5826-4418

** Екатерина Дмитриевна Слободенюк - кандидат социологических наук, доцент, Национальный исследовательский университет «Высшая школа экономики»; старший научный сотрудник, Институт социологии ФНИСЦ РАН, Москва, Россия, eslobodenyuk@hse.ru, https://orcid.org/0000-0002-4255-5050
\end{abstract}

Цитирование: Тихонова Н.Е., Слободенюк Е.Д. (2022) Бедность российских профессионалов: распространенность, причины, тенденции // Мир России. Т. 31. № 1. С. 113-137. DOI: 10.17323/1811-038X-2022-31-1-113-137

\begin{abstract}
Аннотация
Бедность российских профессионалов распространена довольно широко и в коние 2019 года охватывала почти миллион представителей данной группь; еще шире распространена среди них малообеспеченность. Сокрамение бедности профессионалов в сравнении с 1990-ми годами пришлось в основном на середину 2000-х, в то время как в 2010-е годы его темпь начали отставать даже от темпов сокращения среди ряда других профессиональных групп. Бедность и малообеспеченность представителей данной группь обуславливаются прежде всего последствиями поселенческих, отраслевых и региональных неравенств. Роль этой группь причин для попадания в число бедных за 2010-е годы для профессионалов выросла, и ключевыми среди них являются поселенческие неравенства, «стягиваючие» на себя другие их виды. Вторая группа причин объединяет факторы, связанные с размером и характером иждивенческой нагрузки, особенно нагрузки несовершеннолетними детьми. Поскольку зарплата каждого шестого профессионала в России ниже полутора прожиточных минимумов в регионе его проживания, то она не обеспечивает для него даже суженного демографического воспроизводства. Значимость этой группы причин бедности и малообеспеченности профессионалов в последнее десятилетие, несмотря на меры помощи государства семьям с детьми, не уменьшилась. Третья группа причин их бедности связана с различиями в качестве человеческого капитала представителей данной группьы. Вероятность бедности среди профессионалов с низкими его показателями во всех типах поселений относительно выше, чем со средними и высокими, хотя и у имеющих высокие показатели
\end{abstract}

Исследование выполнено за счет гранта РФФИ (проект № 19-29-07172).

Статья поступила в редакцию в октябре 2020 г. 
каждый пятый получает зарплату не более двух прожиточных минимумов в своем регионе. За низкими зарплатами российских профессионалов даже с высоким качеством человеческого капитала кроется традиционная для нашей страны недооченка высококвалифицированного нефизического труда, а их общий зарплатный профиль сейчас мало отличается от профиля других профессиональных групп. При этом такие способы улучшить свое положение, как миграция, смена работы в рамках своего населенного пункта, вторичная занятость и наращивание своего человеческого капитала для них в настоящее время малоэффективны, хотя в той или иной степени ими используются все эти способы.

Ключевые слова: сочиальная структура, профессиональная структура, профессиональ, бедность, малообеспеченность, человеческий капитал, вторичная занятость

Профессионалы, т. е. лица, занимающие рабочие места, которые предполагают высшее образование, традиционно рассматриваются в любом современном обществе как относительно благополучная на фоне остальных работающих социальная группа и основа среднего класса. Это обусловлено тем, что они являются обладателями очень важного для современной экономики вида активов - качественного человеческого капитала. В то же время, учитывая, что цена любого товара, в т. ч. человеческого капитала, определяется соотношением спроса и предложения на соответствующем рынке, может сложиться ситуация, когда в силу избыточности предложения на рынке труда высококвалифицированной рабочей силы ренты на человеческий капитал начинают сокращаться или даже вообще исчезают, что ведет к распространению среди профессионалов безработицы и бедности.

В России с середины 2000-х гг. фиксируются рост безработицы среди лиц с высшим образованием ${ }^{1}$ и снижение отдач от этого уровня образования [Лукьянова 2010; Тихонова, Каравай 2018]. В основе этих процессов - дисбаланс между числом лиц с высшим образованием и численностью предполагающих его рабочих мест ${ }^{2}$ В итоге профессионалы оказались перед растущими рисками безработицы, нестабильной занятости и относительного снижения оплаты их труда. Более того, эти риски могут совместиться в перспективе с последствиями процесса расслоения и поляризации данной профессиональной группы, прекаризации и обеднения значительной ее части под влиянием ускоряющихся во всем мире технологических изменений [Кастельс 2000; Тощенко 2018 и др.]. Актуализирует вопрос о тенденциях ситуации с бедностью профессионалов в России и начавшийся под влиянием пандемии очередной экономический кризис.

Таким образом, типичная для России 1990-х гг. проблема бедности профессионалов к середине 2000-х гг., в связи с быстрым ростом благосостояния всех групп населения казалось бы, прочно ушла из повестки дня. На самом деле она лишь перешла в «тлеющее» состояние и сейчас может вновь обостриться. В то же время бедность представителей данной группы не только является серьезным препятствием для формирования российского среднего класса, но и демотивирует их в наращивании своего человеческого капитала. Более того, она сокращает

1 Доля безработных с высшим образованием в составе безработного населения страны выросла с 11,3\% в 2007 г. [Рабочая сила 2018, с. 115] до 20,7\% в 2018 г. [Труд и занятость 2019, с. 43].

2 В 2018 г. доля лиц с высшим образованием достигла 34,2\% занятых [Труд и занятость 2019, с. 25], при том что количество рабочих мест для специалистов высшей квалификации составляло 24,6\% [Труд и занятость 2019, с. 32]. 
их возможности для наращивания своих знаний и навыков даже при наличии у них соответствующих стремлений. Препятствует она и успешному воспроизводству обладающей наибольшим культурным и человеческим капиталом части населения страны. Невозможность для профессионалов без высоких рисков бедности и малообеспеченности даже простого демографического воспроизводства ведет к сокращению среди них рождаемости и ограниченности их возможностей инвестиций в человеческий капитал своих детей. Немаловажно и то, что недооценка высококвалифицированного труда в стране на фоне нарастающей уравниловки доходов населения [Тихонова 2018] усугубляет потенциал социальной напряженности в российском обществе, а ведь именно протесты населения СССР (и прежде всего наиболее квалифицированной его части) против уравниловки сыграли значительную роль в масштабных трансформациях конца 1980-1990-х гг. Таким образом, последствия бедности и малообеспеченности профессионалов многогранны и чреваты серьезными издержками для развития России в будущем.

Именно эти соображения побудили нас сделать предметом своего исследования проявления в среде российских профессионалов таких явлений, как бедность и малообеспеченность.

\section{Теоретико-методологические основания и эмпирическая база исследования}

Говоря о теоретико-методологических основаниях проведенного исследования, прежде всего следует подробно пояснить, кого мы подразумеваем под профессионалами, поскольку есть несколько традиций их изучения. В концепциях технократического, постиндустриального и информационного обществ под ними обычно подразумеваются представители высококвалифицированного умственного труда [Белл 1999; Гелбрейт 1969; Кастельс 2000 и др.]. Именно работы, относящиеся к этому направлению, сыграли основную роль в изменении отношения к данной группе в обществе и получили наибольшую популярность в мире. Широко распространены также исследования, реализуемые в рамках социологии профессий [Мансуров, Юрченко 2013; Мансуров 2013; Macdonald 1995; Svensson, Evetts 2010 и др.]. В рамках этого направления предметом исследований обычно выступают отдельные профессиональные группы (врачи, инженеры и т. п.). Довольно популярно и представленное в основном экономистами направление, рассматривающее профессионалов через призму эффективного использования человеческих ресурсов, в т. ч. с учетом основных трендов экономического развития [Вишневская 2017; Гимпельсон, Капелюшников 2011; Cedefop 2012 и др.]. Наконец, есть большое число работ, предметом которых выступает изучение профессионалов как особой группы в рамках социальной структуры общества. В фокусе этих работ обычно находятся их слоевая или классовая принадлежность, связь профессиональной структуры и модели социальной структуры общества и специфические особенности их жизни [Любимова и др. 2008; Голенков 2015; Сrоисh 2010 и др.].

Наше исследование относится именно к этой, четвертой, исследовательской традиции. Для выделения профессионалов мы использовали Международный классификатор занятий в его версии 2008 г. (International Standard Classification 
of Occupations, сокращенно ISCO-08) 3 . В основе выделения профессиональных классов в ISCO лежит матрица признаков, учитывающая, с одной стороны, набор видов деятельности, задачи и обязанности при которых имеют высокую степень схожести, а с другой - уровень образования, обеспечивающий способность выполнять задачи и обязанности, предусмотренные этими видами деятельности (для профессионалов это, как правило, высшее образование).

Эмпирической базой исследования выступили репрезентативные версии 9-й, 20-й и 28-й волн РМЭЗ НИУ ВШЭ (далее РМЭЗ). Опросы в рамках этих волн исследования проходили в следующие сроки: в 9-й волне - в октябре-декабре 2000 г. (3949 респондентов от 18 лет и старше, в т. ч. 608 чел., т. е. 16,9\% всех занятых, профессионалы); в 20-й волне - в октябре 2011 - феврале 2012 г. (13669 респондентов от 18 лет и старше, из них 1417 чел., т. е. 18,2\% всех занятых, - профессионалы); в 28-й волне - в октябре-декабре 2019 г. (9916 респондентов от 18 лет и старше, в т. ч. 906 чел., т. е. 17,7\% всех занятых, профессионалы). Эти временные точки анализа относительно равномерно распределяясь по 20-летнему периоду, позволяли проанализировать проблемы бедности профессионалов в сравнительно благополучные моменты новейшей российской истории и оценить динамику ситуации безотносительно к непосредственному воздействию на нее очередных экономических кризисов.

Вторым важным аспектом методологии нашего исследования стал т. н. абсолютный подход к бедности, основанный на сопоставлении доходов населения с экспертно задаваемой их величиной («чертой бедности»). Именно этот подход обычно используется для выделения бедного населения органами государственной власти и статистическими службами России. Поэтому для выявления бедных нами была выбрана методика, концептуально приближенная к используемой Федеральной службой государственной статистики Российской Федерации (ФСГС РФ): «черта бедности» рассчитывалась индивидуально для каждого домохозяйства путем суммирования нормативов прожиточных минимумов (ПМ) в квартале, в котором проводилось исследование, с учетом региона проживания домохозяйства и его состава (количества в нем детей, пенсионеров и людей трудоспособного возраста). Полученная величина соотносилась с совокупным доходом домохозяйства, который указывался респондентом в ходе опроса. К числу бедных в результате были отнесены все домохозяйства, совокупный доход которых оказался меньше рассчитанного для каждого из них совокупного прожиточного минимума.

Следует отметить, что наряду с абсолютным подходом к бедности в мировой науке существует также другой, т. н. относительный подход, используемый обычно в развитых странах 5 . Он существует в двух основных версиях. Это, во-первых, берущая начало еще с работ П. Таунсенда [Townsend 1979] депривационная версия, предполагающая, что бедными являются граждане, испытывающие не характерные для членов определенного сообщества множественные лишения (депривации)

\footnotetext{
3 Подробнее см.: Классификаторы профессий ISCO // https://www.hse.ru/rlms/rlms/classif/isco, дата обращения 25.10.2021; [International Standard Classification of Occupations 2012].

4 Российский мониторинг экономического положения и здоровья населения НИУ ВШЭ (RLMS-HSE), проводимый Национальным исследовательским университетом «Высшая школа экономики» и ООО «Демоскоп» при участии Центра народонаселения Университета Северной Каролины и Института социологии ФНИСЦ РАН. Сайт обследования RLMS-HSE // http://www.hse.ru/rlms, дата обращения 26.10.2021.

5 Субъективная бедность - принципиально иной социальный феномен, поэтому на ее характеристике мы здесь не останавливаемся.
} 
и не способные поддерживать типичный для него образ жизни. А во-вторых, это монетарная версия относительного подхода, предполагающая, что определенный уровень доходов по отношению к медианным (реже - средним) для данного сообщества заведомо обрекает их обладателей на невозможность поддерживать типичный для них образ жизни ${ }^{6}$. Как было показано в [Тихонова 2018], для современного российского общества невозможность поддерживать типичный для массовых слоев населения образ жизни, а также наличие не характерных для них лишений начинают доминировать при доходах менее 0,75 медианы доходного распределения в массовых слоях населения в соответствующем регионе. Поскольку в последнее время ФСГС РФ все чаще используется относительный подход к бедности, а в ближайшие годы произойдет переход к нему и в государственной социальной политике, то мы рассчитали и число профессионалов с доходами не более 0,75 медианных. Таковых осенью 2019 г., согласно данным РМЭ3, было 13,4\% от всех профессионалов. Это значит, что относительная бедность распространена среди них примерно вдвое шире, чем абсолютная, и в их число попадает значительная часть группы, которую мы определили как «малообеспеченные».

Бедность россиян в целом в различных интерпретациях данного феномена изучается достаточно активно [Карабчук и др. 2013; Овчарова 2012; Ярошенко 2010 и др.]. В то же время бедность профессионалов как не типичное для них состояние практически не являлась в последние два десятилетия предметом самостоятельного изучения, хотя в 1990-е гг., когда бедность носила массовый характер и обеднение затронуло даже тех, кто обычно занимает устойчивые позиции на рынке труда и имеет предполагающий относительно высокие доходы высокий уровень квалификации, данный сюжет находился в поле зрения российских ученых. Этих россиян тогда называли «новыми бедными». При этом, однако, за этим широко использовавшимся термином у разных авторов скрывался существенно различный смысл. Чаще всего под ними подразумевали обедневших работников квалифицированного нефизического труда [Заславская 1996, с. 19; Тихонова 2003, с. 88-92; Чернина 1994, с. 57 и др.]. Тем не менее в других публикациях (например, [Радаев 2000, с. 25]) понятия «новые бедные» и «работающие бедные» использовались как синонимы. Впоследствии, в 2000-2010-х гг., понятие «новые бедные» практически ушло из лексикона отечественных ученых, а ситуация с бедностью профессионалов и ее причинами, за редкими исключениями [Горшков, Тихонова 2014; Тихонова 2013 и др.], не становилась предметом анализа даже косвенно.

Характеризуя методологические и методические предпосылки нашего исследования, необходимо уточнить также, что в своем анализе мы рассматривали не только бедность, но и малообеспеченность профессионалов как еще одну разновидность их социального неблагополучия. Под малообеспеченностью мы подразумевали среднедушевые доходы, которые выше «черты бедности», но не превышают полутора прожиточных минимумов для домохозяйств соответствующей структуры в конкретном регионе. Выбор данного значения прожиточного минимума как границы малообеспеченности отчасти учитывал расширенный, по сравнению со среднестатистическим россиянином, набор потребностей представителей данной группы, особенно в сфере потребления культурных благ и образования (как собственного, так и своих детей), а отчасти - его нетипичность для профессионалов, свидетельствующую об относительном неблагополучии обладающих таким уровнем доходов.

6 Подробнее о различных подходах к бедности см. [Овчарова 2012; Тихонова 2018] и др. 
Таблица 1. Распределение работающих россиян и профессионалов по показателям Индекса ЧК, 2019 г., \% ${ }^{7}$

\begin{tabular}{|l|c|c|}
\hline Баллы & Доля среди всех работающих & Доля среди профессионалов \\
\hline 0 баллов & 4,1 & 0,1 \\
\hline 1 балл & 22,3 & 1,7 \\
\hline 2 балла & 16,5 & 4,4 \\
\hline 3 балла & 8,7 & 5,6 \\
\hline 4 балла & 8,6 & 7,4 \\
\hline 5 баллов & 6,8 & 8,4 \\
\hline 6 баллов & 7,1 & 12,3 \\
\hline 7 баллов & 7,2 & 14,6 \\
\hline 8 баллов & 5,6 & 12,3 \\
\hline 9 баллов & 6,5 & 15,2 \\
\hline 10 баллов & 3,2 & 8,0 \\
\hline 11 баллов & 2,0 & 5,3 \\
\hline 12 баллов & 0,7 & 2,2 \\
\hline 13 баллов & 0,7 & \\
\hline
\end{tabular}

Наконец, последнее, о чем следует сказать в связи с характеристикой теоретико-методологических и методических оснований нашего исследования, - это понятие «человеческий капитал», которое интерпретируется в данной статье в соответствии с его классической концепцией [Becker 1964]. Эта концепция исходит из того, что в обществах позднеиндустриального типа знания работника становятся для экономики в целом одним из важнейших факторов производства, а для него самого - одним из его ключевых активов. Соответственно, работник должен получать на эти знания стимулирующие их накопление доходы, аналогичные доходу на инвестиции в другие виды капитала.

Неоднократные расчеты отдач на высшее образование в России продемонстрировали, что ренты на сам факт наличия высшего образования и на продолжительность периода обучения присутствуют и в нашей стране [Лукьянова 2010;

7 Серым фоном выделены ячейки с наибольшими показателями, в сумме объединяющие более $50 \%$ группы, т. е. типичные для нее. 
Тихонова 2017; Тихонова, Каравай 2018]. При этом иногда учитываются и другие характеристики знаний и навыков профессионалов, в частности знание иностранных языков, основных компьютерных программ и т. п.

Принимая во внимание разнообразие способов измерения человеческого капитала, существующее сейчас в науке, и многообразие его рентоприносящих компонентов, в качестве индикаторов его состояния у профессионалов мы рассматривали и наличие высшего образования, и показатели специального Индекса человеческого капитала (Индекс ЧК или ИЧК), который рассчитывался нами на основе показателей двух шкал ${ }^{8}$. Возможные значения этого Индекса находились в диапазоне от 0 до 13 баллов. Для работающего населения страны и профессионалов показатели этого Индекса различались довольно существенно (таблица 1). Медианное значение Индекса среди работающего населения страны старше 18 лет составляло 3 балла, а среди профессионалов - 7 баллов.

Основываясь на доле профессионалов с разными значениями Индекса ЧК, мы рассматривали значения этого Индекса для них в 0-5 баллов как низкие, 6-7 баллов - как средне-низкие, 8-9 - как средне-высокие, а в 10-13 - как высокие, поскольку эти значения ИЧК нетипичны в России даже среди профессионалов (таблица 1).

\section{Масштабы и динамика бедности российских профессионалов}

По состоянию на конец 2019 г. бедность среди профессионалов была распространена в России довольно широко (6,3\%), хотя и встречалась заметно реже, чем среди работающего населения в целом $(11,4 \%)$. Малообеспеченность их имела еще более массовый характер: 15,3\% профессионалов имели среднедушевые доходы в своих домохозяйствах менее полутора прожиточных минимумов (при 21,7\% среди всех работающих). При этом доходы большинства профессионалов были близки к доходам в домохозяйствах квалифицированных и даже неквалифицированных рабочих в тех же регионах (рисунок 1), хотя риски бедности и малообеспеченности у рабочих были все же выше.

Тем не менее нынешняя картина доходов профессионалов выглядит все же гораздо лучше, чем она выглядела в 2000 и 2011 гг. (таблица 2). Массовое обеднение в 1990-х гг. этой наиболее квалифицированной части общества к концу 2010-х было в целом преодолено, однако принципиальные изменения в этом отношении произошли еще до кризиса 2008-2009 гг.

Кроме того, доля бедных среди них уменьшалась в начале 2020-х гг. даже меньшими темпами, чем среди неквалифицированных рабочих, что также говорит

\footnotetext{
8 Ключевой являлась шкала «Количество лет обучения». Именно ее показатели, согласно традиции анализа человеческого капитала в его классической трактовке, свидетельствуют об объеме накопленных человеком знаний, о выработанном им навыке обучаемости, степени его социализированности и т. д. Обучению различной продолжительности соответствовали разные баллы - за обучение менее 10 лет баллы не присваивались; за 10-12 лет обучения присваивался 1 балл, а начиная с 13 лет обучения каждый год давал 1 дополнительный балл. Шкала «Навыки» состояла из двух субшкал - «Знание иностранных языков» и «Владение компьютерными технологиями». За наличие соответствующих навыков можно было получить максимум 2 балла по каждой субшкале, затем эти баллы суммировались. Индекс человеческого капитала рассчитывался по итогам агрегирования показателей шкал «Количество лет обучения» и «Навыки». Подробное описание этого Индекса см. [Тихонова, Каравай 2017].
} 
о том, что вряд ли ситуацию с динамикой их доходов можно однозначно оценивать как благополучную: так, хотя с 2011 по 2019 г. доля бедных среди профессионалов сократилась в 1,4 раза, среди неквалифицированных рабочих это сокращение было полуторакратным.

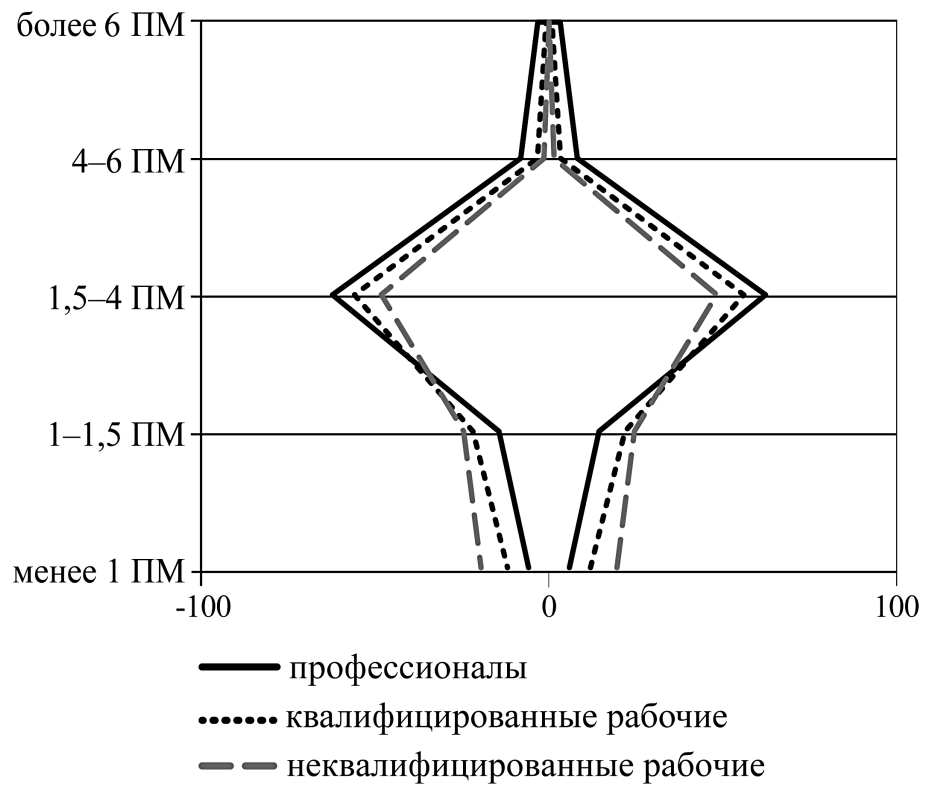

Рисунок 1. Среднедушевые доходы в домохозяйствах представителей различных профессиональных групп в соотношении с региональным прожиточным минимумом (ПМ) для домохозяйств соответствующей структуры, 2019 г., \%

Таблица 2. Соотношение бедных, малообеспеченных и благополучных профессионалов по их доходам в различные годы, 2000/2011/2019 гг., \%

\begin{tabular}{|l|c|c|c|}
\hline Групшы & $\mathbf{2 0 0 0}$ г. & $\mathbf{2 0 1 1}$ г. & $\mathbf{2 0 1 9}$ г. \\
\hline $\begin{array}{l}\text { Благополучные } \\
\text { среднедушевые доходы в домохозяйствах свыше 1,5 ПМ) }\end{array}$ & 24,8 & 72,0 & 78,4 \\
\hline $\begin{array}{l}\text { Малообеспеченные } \\
\text { (среднедушевые доходы в домохозяйствах от 1 до 1,5 ПМ) }\end{array}$ & 20,7 & 19,2 & 15,3 \\
\hline $\begin{array}{l}\text { Бедные } \\
\text { (среднедушевые доходы в домохозяйствах менее 1 ПМ) }\end{array}$ & 54,5 & 8,8 & 6,3 \\
\hline
\end{tabular}




\section{Основные причины бедности российских профессионалов макроуровня}

Доходы профессионалов предопределяются прежде всего размером оплаты их труда, следовательно, основными причинами их бедности являются факторы, влияющие на уровень их зарплаты. Согласно данным РМЭЗ, в конце 2019 г. средняя зарплата профессионалов составляла после вычета налогов 34733 руб. ${ }^{9}$ при 29293 руб. по работающим в среднем. Это свидетельствует о недооценке высококвалифицированного нефизического труда в российской экономике, обусловленной как сложившимися еще в советское время в силу бесплатности высшего образования и господства установок на социальную однородность общества традициями, так и дисбалансом спроса и предложения на соответствующем сегменте рынка труда, уже упоминавшимся выше.

При этом относительно невысокая зарплата профессионалов очень сильно дифференцирована по типам поселений, что создает для них в малых городах и селах повышенные риски бедности и малообеспеченности: так, если в Москве их медианная зарплата составляла в конце 2019 г., по данным РМЭ3, 50 тыс. руб., то в центрах субъектов РФ - уже 30 тыс. руб., в прочих городах - 27 тыс. руб., а в селах - 22 тыс. руб. Отчасти в такой дифференциации «виновата» отраслевая структура занятости: так, 55,9\% сельских профессионалов были заняты по состоянию на конец 2019 г. в образовании - отрасли, зарплата в которой вообще ниже, чем в среднем среди профессионалов; еще $12,4 \%$ сельских профессионалов работали в учреждениях культуры и 4,0\% - в сельском хозяйстве, т. е. в отраслях, также характеризующихся относительно низкими зарплатами. В то же время профессионалы из отраслей с наиболее высокими зарплатами концентрируются в основном в крупных городах ${ }^{10}$.

На типах поселений во многом замыкаются не только межотраслевые, но и внутриотраслевые различия. Зарплата профессионалов зависит также и от размеров предприятий, на которых они заняты: чем крупнее предприятие, тем выше на нем в среднем зарплаты. А поскольку в крупных населенных пунктах вероятность встретить большие предприятия относительно выше, то в республиканских, краевых и областных центрах, а тем более в Москве или Санкт-Петербурге, не только выше оказывается доля высокооплачиваемых профессионалов, но и дифференциация их зарплат соответственно глубже. Оборотной стороной этого выступает сравнительно меньшая дифференциация их зарплат на предприятиях одного размера в разных типах поселений, в т. ч. на предприятиях

\footnotetext{
9 Согласно данным ФСГС РФ, среднемесячная зарплата в октябре 2019 г., т. е. в момент начала опроса РМЭЗ, составляла у специалистов высшей квалификации 48848 руб. [ФСГС РФ 2020, табл. 24] (42498 руб. за вычетом подоходного налога). Отчасти разница зарплат по статистическим и социологическим данным объясняется нюансами выделения группы профессионалов при использовании разных классификаторов занятий, отчасти - непопаданием наиболее высокооплачиваемых специалистов, зарплаты которых учитываются ФСГС РФ, в выборки массовых опросов, а отчасти - спецификой методик расчета заработной платы ФСГС РФ и в социологических исследованиях. Тем не менее в обоих вариантах зарплаты профессионалов относительно невысоки.

10 О значимом влиянии отрасли занятости на размер зарплаты профессионалов говорят и данные государственной статистики. Лидерами по размеру зарплат, согласно укрупненной классификации занятий, выступают специалисты по информационно-коммуникационным технологиям (средняя зарплата - 73046 руб.), а аутсайдерами специалисты в области образования (37910 руб.) [ФСГС РФ 2020, табл. 6].
} 
одной отрасли: так, в наиболее массовой с точки зрения занятости специалистов отрасли (образовании ${ }^{11}$ ) разрывы в ее размерах у профессионалов были в 2019 г., согласно данным РМЭ3, 13-кратные. При этом на малых предприятиях данной отрасли они составляли 10,9 раз, а на малых предприятиях в крупных городах - 6,9 раз.

Заметно дифференцирует зарплату профессионалов и занятость на предприятиях или в организациях государственного и частного секторов экономики. Хотя этот фактор влияет, как и упомянутые выше, на зарплаты всех профессиональных групп, но профессионалы относятся к тем из них, на которые он оказывает наиболее сильное влияние (таблица 3), что отчасти связано с отраслевой спецификой этих секторов.

Таблица 3. Дифференциация зарплат представителей различных профессиональных групі в государственном и негосударственном секторах экономики, 2019 г., \% ${ }^{12}$ (отранжировано по величине разрыва средних зарплат между секторами)

\begin{tabular}{|c|c|c|c|}
\hline \multirow{2}{*}{ Профессиональные групшы } & \multicolumn{2}{|c|}{ Среднее по профессиональной групше } & \multirow[b]{2}{*}{ Разрыв, раз } \\
\hline & $\begin{array}{l}\text { государственный } \\
\text { сектор }\end{array}$ & $\begin{array}{l}\text { негосударственный } \\
\text { сектор }\end{array}$ & \\
\hline Руководители & 33719 & 48860 & 1,45 \\
\hline Профессионалы & 30731 & 42667 & 1,39 \\
\hline Полупрофессионалы & 25358 & 33384 & 1,32 \\
\hline $\begin{array}{l}\text { Неквалифицированные рабочие } \\
\text { всех отраслей }\end{array}$ & 15663 & 20420 & 1,30 \\
\hline $\begin{array}{l}\text { Служащие офисные } \\
\text { и по обслуживанию клиентов }\end{array}$ & 22895 & 28756 & 1,26 \\
\hline Работники сферы торговли и услуг & 20234 & 22181 & 1,10 \\
\hline $\begin{array}{l}\text { Квалифицированные рабочие } \\
\text { (ручной труд) }\end{array}$ & 28352 & 30322 & 1,10 \\
\hline $\begin{array}{l}\text { Квалифицированные рабочие } \\
\text { (машины и механизмы) }\end{array}$ & 31193 & 31371 & 1,00 \\
\hline
\end{tabular}

Таким образом, выходя на рынок труда по месту жительства, профессионалы оказываются в рамках довольно жесткой сетки внешних структурных ограничений. Именно место жительства, с учетом различий структуры экономики отдельных регионов и типов поселений, во многом предопределяет для них возможность занятости на предприятиях той или иной отрасли, больших/средних/малых или

\footnotetext{
11 В образовании занято 1795,9 тыс. из 4854,0 тыс. российских профессионалов [ФСГС РФ 2020, табл. 6].
}

12 Зарплаты по основному месту работы после уплаты подоходного налога. 
микро-, относящихся к государственному или негосударственному сектору и находящихся в активно развивающихся или депрессивных локациях ${ }^{13}$. Все эти факторы сказываются и на рисках для них оказаться за чертой бедности или в числе малообеспеченных. При этом в особенно тяжелое положение попадают профессионалы в сельской местности, составляющие свыше половины $(59,3 \%)$ находящихся за чертой бедности представителей данной группы; вместе с тем с годами отчетливо прослеживается тенденция все большей локализации бедных профессионалов именно в селах (таблиц̧а 4).

Таблица 4. Место жительства профессионалов с разным уровнем среднедушевых доходов, 2000/2011/2019 гг., \% ${ }^{14}$

\begin{tabular}{|c|c|c|c|}
\hline Место жительства & Благополучные & $\begin{array}{l}\text { Малообеспе- } \\
\text { ченные }\end{array}$ & Бедные \\
\hline \multicolumn{4}{|l|}{2019 г. } \\
\hline $\begin{array}{l}\text { Москва, Санкт-Петербург, республиканские, } \\
\text { краевые, областные центры }\end{array}$ & 54,1 & 38,9 & 13,0 \\
\hline Прочие города & 26,9 & 20,6 & 24,1 \\
\hline Поселки городского типа & 4,2 & 13,0 & 3,7 \\
\hline Села & 14,8 & 27,5 & 59,2 \\
\hline \multicolumn{4}{|l|}{2011 г. } \\
\hline $\begin{array}{l}\text { Москва, Санкт-Петербург, республиканские, } \\
\text { краевые, областные центры }\end{array}$ & 55,3 & 33,0 & 17,4 \\
\hline Прочие города & 24,4 & 29,0 & 22,6 \\
\hline Поселки городского типа & 5,8 & 6,3 & 16,5 \\
\hline Села & 14,5 & 31,7 & 43,5 \\
\hline \multicolumn{4}{|l|}{2000 г. } \\
\hline $\begin{array}{l}\text { Москва, Санкт-Петербург, республиканские, } \\
\text { краевые, областные центры }\end{array}$ & 69,0 & 55,4 & 45,1 \\
\hline Прочие города & 22,1 & 28,1 & 24,8 \\
\hline Поселки городского типа & 4,8 & 6,6 & 6,0 \\
\hline Села & 4,1 & 9,9 & 24,1 \\
\hline
\end{tabular}

13 РМЭЗ не репрезентирует население страны по регионам, однако, как следует из данных ФСГС РФ, региональная дифференциация зарплат профессионалов также очень велика. Так, если в Дагестане и Кабардино-Балкарии средняя зарплата специалистов высшей квалификации составляла в октябре 2019 г. 24914 и 25449 руб. соответственно, то в Чукотском и Ямало-Ненецком автономных округах - 103048 и 92118 руб. соответственно (в Москве этот показатель достигал 86360 руб.) [ФСГС РФ 2020, табл. 34].

14 Серым фоном выделены ячейки, показатели в которых превышают 50\%, т. е. типичны для соответствующей группы. 
В целом значимость всех факторов бедности профессионалов, относящихся к макроуровню, за 2010-е гг. выросла, о чем свидетельствует динамика коэффициентов Спирмена (таблица 5), причем в наибольшей степени среди этих факторов значимы характеристики, относящиеся к месту жительства профессионалов. Форма собственности и размер предприятия, а также отрасль их занятости увеличили свою значимость для риска оказаться в числе бедных в течение 2010-х гг., но все же остаются гораздо менее значимыми.

Таблица 5. Коэффициент Спирмена для различных характеристик занятости и места жительства профессионалов, с одной стороны, и их принадлежности к группам бедных или небедных - с другой, 2011/2019 гг., \%

\begin{tabular}{|l|c|c|}
\hline Характеристики & $\mathbf{2 0 1 1}$ г. & $\mathbf{2 0 1 9}$ г. \\
\hline Тип поселения & 0,224 & 0,245 \\
\hline Численность его жителей & 0,219 & 0,252 \\
\hline Размер предприятия & 0,052 & 0,111 \\
\hline Государственное/негосударственное & 0,007 & 0,067 \\
\hline Отрасль & 0,028 & 0,039 \\
\hline
\end{tabular}

Для рисков малообеспеченности роль типа поселения и численности жителей в нем за 2010-е гг., в отличие от ситуации с бедностью, сократилась, хотя также осталась наиболее значимой. Однако значимость других факторов макроуровня для рисков малообеспеченности при этом не изменилась.

\section{Основные причины бедности российских профессионалов микроуровня}

Разнонаправленные тенденции динамики роли места жительства для бедности и малообеспеченности связаны с тем, что это разные по своей природе феномены, их различие ярко проявляется при обращении к факторам микроуровня, усиливающим их риски. Малообеспеченность профессионалов относительно сильнее связана с размером домохозяйств и количеством несовершеннолетних детей. Бедность же при всей значимости для нее этих факторов относительно сильнее связана у профессионалов, если говорить только о факторах микроуровня с качеством их человеческого капитала, прежде всего с их уровнем образования (таблица б).

Таким образом, бедность в большей степени, чем малообеспеченность, связана с позицией на рынке труда, определяемой спецификой знаний и навыков профессионалов, в то время как малообеспеченность в большей степени обуславливается факторами социально-демографического характера, однако это не значит,

15 Серым фоном выделены ячейки, показатели корреляции в которых статистически значимы на уровне 0,01 . Остальные значимы на уровне 0,05 . 
что бедность не зависит от этих факторов. Вероятность оказаться в числе бедных у профессионалов из крупных семей (4 чел. и более) в 4,5 раза выше, чем у имеющих семьи меньшего размера; у профессионалов, проживающих с детьми не старше 16 лет, - в 5,6 раз выше, чем у тех, в чьих семьях нет детей. Это говорит о том, что зарплаты многих российских профессионалов не предусматривают возможность даже простого демографического воспроизводства, и улучшений в данной области, несмотря на меры господдержки семей с детьми, практически не наблюдается ${ }^{16}$.

Таблица 6. Коэффициент Спирмена для различных характеристик места жительства, домохозяйств и человеческого капитала профессионалов, с одной стороны, и их принадлежности к группам бедных или малообеспеченных - с другой, 2019 г., \% ${ }^{17}$

\begin{tabular}{|l|c|c|}
\hline Характеристики & Бедность & Малообеспеченность \\
\hline $\begin{array}{l}\text { Количество несовершеннолетних детей } \\
\text { в домохойсте }\end{array}$ & 0,196 & 0,322 \\
\hline Размер домохозяйства & 0,188 & 0,309 \\
\hline Тип поселения & 0,245 & 0,263 \\
\hline Возраст & 0,093 & 0,143 \\
\hline Законченное образование & 0,206 & 0,148 \\
\hline Наличие высшего образования & 0,204 & 0,145 \\
\hline Очный характер высшего образования & 0,191 & 0,158 \\
\hline Индекс человеческого капитала & 0,152 & 0,105 \\
\hline
\end{tabular}

Не останавливаясь подробнее на этой стороне проблемы бедности профессионалов, поскольку роль связанных с размером и структурой домохозяйства факторов в формировании бедности в России подробно освещена в отечественной литературе [Овчарова и др. 2011; Пишняк, Попова 2011; Слободенюк 2013 и др.], рассмотрим вторую группу причин микроуровня, связанную с рисками их бедности. Мы имеем в виду различия в качестве человеческого капитала профессионалов, которое заметно сказывается на размерах их зарплаты: если среди имеющих высшее образование она составляла в конце 2019 г. в среднем 36884 руб., то у не имеющих его - 27009 руб.

Сильно влияют на зарплату профессионалов (и, соответственно, - на их риски обеднения) и значения Индекса человеческого капитала (таблища 7). При этом

16 Почти половина $(45,6 \%)$ профессионалов, в домохозяйствах которых проживает двое детей, относились в 2019 г. к числу бедных и малообеспеченных, в т. ч. 11,8\% имели доходы ниже прожиточного минимума. В 2011 г. эти показатели составляли 47,9\% и 13,4\% соответственно, т. е. ситуация остается в этом отношении практически неизменной.

17 Все корреляции статистически значимы на уровне 0,01. Серым фоном выделены ячейки, значения в которых максимальны по строке. 
перелом по распространенности бедности проходит на границе между 5 и 6 баллами ${ }^{18}$ ИЧК, которая разделяет профессионалов, соответствующих и не соответствующих минимальным требованиям к ним в современной экономике.

Таблица 7. Заработная плата ${ }^{19}$ и распространенность бедности в группах профессионалов с разными значениями Индекса человеческого капитала, 2019 г.

\begin{tabular}{|l|c|c|c|}
\hline Значения Ичк & $\begin{array}{c}\text { Средняя зарплата, } \\
\text { руб. }\end{array}$ & $\begin{array}{c}\text { Медианная зарплата, } \\
\text { руб. }\end{array}$ & $\begin{array}{c}\text { Доля бедных } \\
\text { среди профессионалов } \\
\text { с соответствующими значениями } \\
\text { ИЧк, \% }\end{array}$ \\
\hline $\begin{array}{l}\text { Высокие } \\
(10-13 \text { баллов) }\end{array}$ & 43214 & 35000 & 3,2 \\
\hline $\begin{array}{l}\text { Средне-высокие } \\
(8-9 \text { баллов) }\end{array}$ & 37217 & 30000 & 3,4 \\
\hline $\begin{array}{l}\text { Средне-низкие } \\
\text { (6-7 баллов) }\end{array}$ & 34020 & 27600 & 4,3 \\
\hline $\begin{array}{l}\text { Низкие } \\
(0-5 \text { баллов) }\end{array}$ & 27577 & 17000 & 14,0 \\
\hline
\end{tabular}

Оценивая данные таблицы 7, стоит помнить, однако, что в них «зашиты» и другие неравенства, уже упоминавшиеся, выше, поскольку, например, для профессионалов, проживающих в селах, типичны низкие значения ИЧК, а для проживающих в крупных городах, напротив, относительно высокие (рисунок 2). О более низком качестве человеческого капитала сельских профессионалов свидетельствует и их уровень образования: если в Москве, Санкт-Петербурге и центрах субъектов РФ доля не имеющих высшего образования среди профессионалов составляла, по данным РМЭ3, в конце 2019 г. всего 15,8\%, то в селах таких было более чем вдвое больше (36,2\%), при этом лишь треть $(35,6 \%)$ всех профессионалов в сельской местности получили образование на очном отделении вузов (при $65,5 \%$ в столицах и центрах субъектов РФ $)^{20}$.

И хотя для всех типов поселений характерна большая вероятность относительно высоких зарплат при более качественном человеческом капитале, она везде составляет менее 50\%. Кроме того, качество человеческого капитала влияет на уровень зарплат в разных типах населенных пунктов по-разному. В крупных городах с их широкими рынками труда и в среднем более высокой зарплатой положение даже имеющих низкие значения ИЧК профессионалов относительно неплохое: лишь 28,5\% из них имели доходы ниже прожиточного минимума в их регионах, в то время как в селах среди профессионалов с относительно низкими

\footnotetext{
18 Показатель 6 баллов по ИЧК означает продолжительность периода обучения 15 лет и наличие навыка владения компьютером.

19 Для имеющих несколько мест занятости - на основной работе.

20 Подробнее о поселенческой дифференциации качества человеческого капитала профессионалов см. [Tихонова 2020а].
} 
значениями ИЧК таких было 68,8\%. Повышает, хотя и в меньшей степени, относительно низкое качество человеческого капитала во всех типах поселений и риски малообеспеченности.

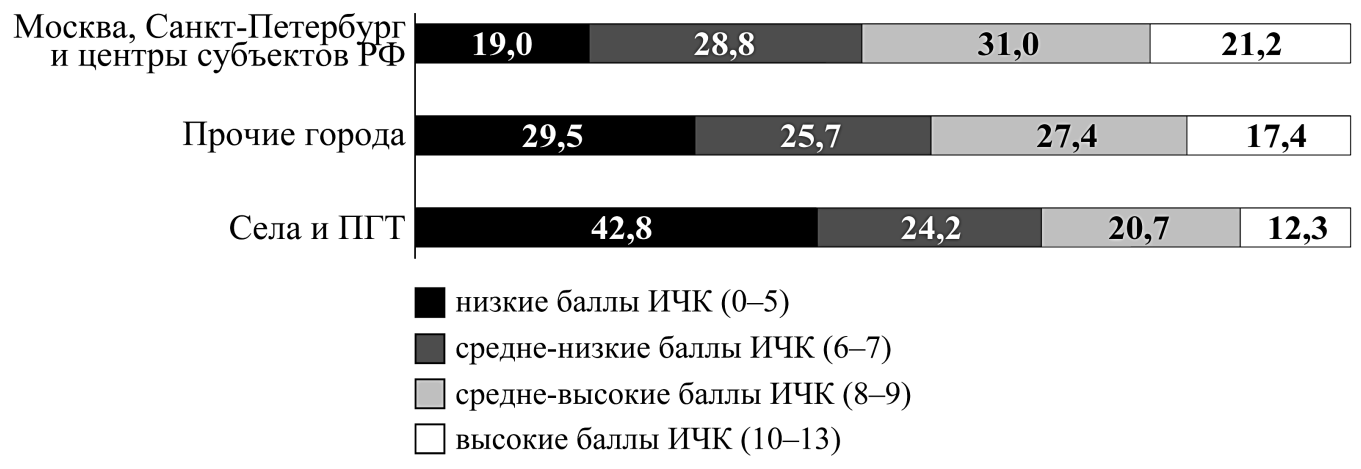

Рисунок 2. Значения ИЧК у профессионалов, проживающих в разных типах поселений, 2019 г., \%

Отдельно оговоримся, что эти различия не связаны с возрастной структурой профессионалов из разных типов поселений, поскольку в крупных городах и в селах их средний возраст в конце 2019 г. был, по данным РМЭЗ, практически одинаков - 42,3 и 42,7 лет соответственно. Более того, зарплатный профиль профессионалов из разных возрастных групп также различается мало, и единственным исключением в этом отношении являются работающие пенсионеры из данной группы, среди которых 80,3\% получали в конце 2019 г. зарплаты не выше 0,75 от медианных зарплат для их типов поселений.

\section{Способы снизить риски бедности у российских профессионалов}

В условиях сильной дифференциации зарплат и рисков бедности в разных типах поселений представляется не удивительным, что одним из ключевых способов улучшения своего положения для профессионалов выступает переезд на другое место жительства, т. е. миграция. Однако, как уже отмечалось отечественными учеными, в последние годы фиксируется тенденция к сокращению миграции представителей данной профессиональной группы, причем довольно четко выраженная: только за период с 2011 по 2017 г. доля профессионалов, имеющих личный опыт миграции, сократилась с 31,4 до 24,0\%. При этом сокращение произошло за счет тех, кто мигрировал за последние 10 лет (их число уменьшилось вдвое) [Латова 2021]. Эти выводы подтверждают и наши данные: лишь 2,4\% профессионалов, согласно данным РМЭЗ 2019 г., переехали в тот населенный пункт, где они жили в момент опроса, после 2011 г.; для предыдущего десятилетия этот показатель достигал 4,2\%, а для периода 1990-х гг. - даже 5,4\%, т. е. был более чем вдвое выше, чем в 2010-е гг. 
Таким образом, популярность миграции как средства решения своих проблем среди профессионалов постепенно уменьшается. Это связано, видимо, с тем, что у наименее благополучной их части отсутствуют ресурсы, требующиеся для переезда (финансовые средства, ресурс социальных сетей и т. д.). Кроме того, качество их человеческого капитала делает для многих из них такой переезд малоперспективным в силу их относительно низкой конкурентоспособности на рынках труда крупных городов. Что же касается специалистов с качественным человеческим капиталом, то смена места жительства внутри страны чаще всего не оказывает влияния на их личный доход, поскольку эффект от выхода на более широкий рынок труда нивелируется для них отсутствием ресурса социальных сетей, играющего в современной России большую роль в трудоустройстве на наиболее привлекательные рабочие места [Тихонова 2020b].

Еще одним важным способом повысить свои доходы является вторичная занятость, которая среди профессионалов распространена мало: в конце 2019 г. ее имели лишь 4,6\%, при этом она обеспечивала лишь поддержание того же доходного профиля, что и у тех, кто имеет только одну работу (рисунок 3 ).

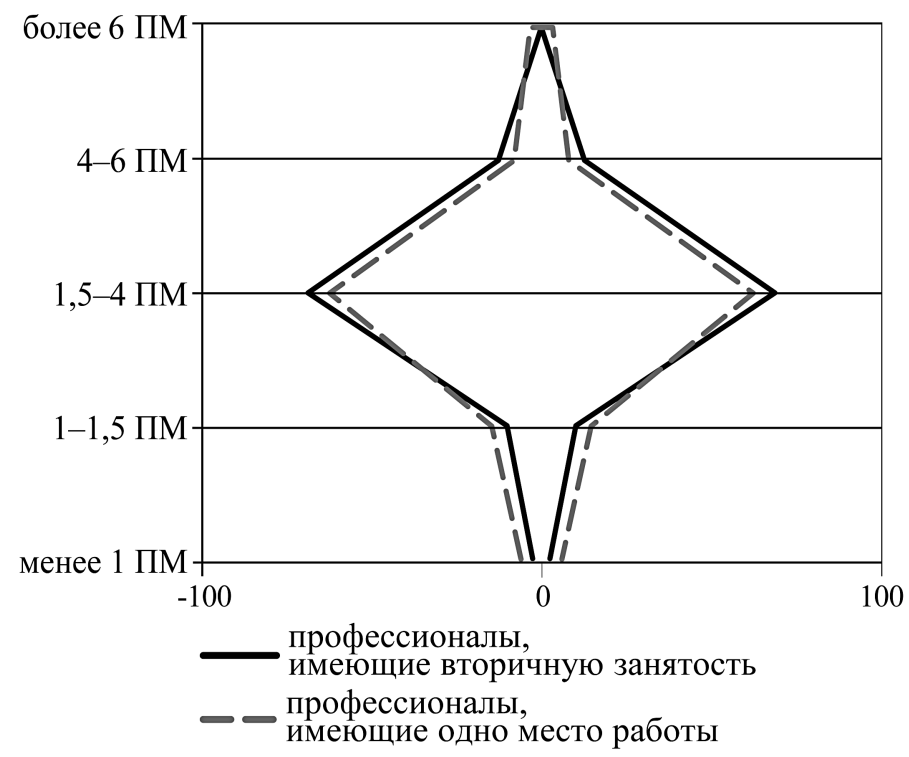
Рисунок 3. Среднедушевые доходы в домохозяйствах профессионалов, имеющих и не имеющих вторичную занятость, в сопоставлении с региональным прожиточным минимумом (ПМ) для домохозяйств соответствующей структуры, 2019 г., \%

Эта парадоксальная ситуация обусловлена тем, что на дополнительную работу сейчас выходят обычно те, у кого на основной работе заработная плата относительно низка (24 тыс. руб. по медиане при 30 тыс. руб. у не имеющих вторичной занятости). 
В этой связи стоит отметить, что за 2010-е гг. вторичная занятость приобрела для профессионалов иной смысл. В 2011 г. и имевшие, и не имевшие ее на основной работе получали практически одинаковую зарплату (15 тыс. руб. по медиане). Вторичная занятость в этих условиях выступала скорее средством улучшить свое положение по отношению к не имеющим ее, чем способом преодолеть риски бедности. Возможно, именно поэтому вторичная занятость среди профессионалов была тогда распространена почти вдвое шире (8,0\%), чем в 2019 г., а малообеспеченность и бедность встречались среди имевших ее в разы реже, чем среди ограничивающихся только одним местом работы (5,8 против 20,4\% для малообеспеченности и 6,8 против 9,0\% для бедности). При этом нагрузка у тех, кто имеет вторичную занятость, среди профессионалов довольно велика и на 10 часов в неделю (по медиане) превышала по состоянию на конец 2019 г. продолжительность рабочей недели у не имевших дополнительной работы (на 2 часа больше, чем у имевших вторичную занятость в 2011 г.).

Вторичная занятость доступна в современной России, как, впрочем, и в 2011 г., в большей степени тем профессионалам, качество человеческого капитала которых в среднем выше, чем у не имеющих ее (таблица 8). С учетом их относительно более низких, чем у остальных профессионалов, зарплат такое положение дел является еще одним свидетельством того, что высокое качество человеческого капитала в современной России далеко не всегда обеспечивает даже средние зарплаты.

Таблица 8. Показатели качества человеческого капитала профессионалов, имеющих и не имеющих вторичную занятость, 2019 г., \% ${ }^{21}$

\begin{tabular}{|c|c|c|}
\hline Показатели & $\begin{array}{c}\text { Имеющие } \\
\text { одно место работы }\end{array}$ & $\begin{array}{c}\text { Имеющие } \\
\text { вторичную занятость }\end{array}$ \\
\hline \multicolumn{3}{|l|}{ Образование, подтвержденное дипломом } \\
\hline Ниже среднего специального & 5,0 & 4,8 \\
\hline Среднее специальное & 17,9 & 14,2 \\
\hline Высшее & 77,1 & 81,0 \\
\hline \multicolumn{3}{|l|}{ Значения Индекса человеческого капитала } \\
\hline $0-5$ & 28,1 & 19,0 \\
\hline $6-7$ & 27,3 & 16,6 \\
\hline $8-9$ & 27,6 & 26,2 \\
\hline $10-13$ & 17,0 & 38,2 \\
\hline Медиана & 7,0 & 9,0 \\
\hline Среднее & 7,0 & 8,1 \\
\hline \multicolumn{3}{|l|}{ Другие характеристики качества человеческого капитала } \\
\hline Очный характер обучения при получении специальности & 54,7 & 59,5 \\
\hline ДПО по профилю занятости в течение последнего года & 4,1 & 9,5 \\
\hline
\end{tabular}

21 Серым фоном выделены ячейки с более высокими значениями в каждой строке. 
Последнее обстоятельство свидетельствует о проблематичности для многих представителей данной профессиональной группы использования такого способа предотвращения попадания в число бедных или малообеспеченных, как наращивание качества своего человеческого капитала. Как уже упоминалось выше, его классическая концепция гласит, что инвестиции в этот вид капитала должны приносить его обладателю дополнительный доход. Однако отдача на наличие диплома о высшем образовании стала в России к концу 2010-х гг. среди профессионалов в среднем даже ниже, чем среди представителей других профессиональных групп, включая квалифицированных рабочих [Тихонова 2017; Тихонова, Каравай 2018]. Такая ситуация является результатом тенденций, сформировавшихся еще в середине 2000-х гг. Как уже отмечалось отечественными учеными [Лукьянова 2010], с 2003 по 2007 г. снижение отдачи на продолжительность обучения составляло в России в расчете на год $1-1,5$ п. п. Однако если в 2000-х гг. отдачи на каждый дополнительный год обучения еще росли, хотя и более медленными темпами, чем в 1990-х гг., когда наблюдался их интенсивный рост (с 4 до 8\% за каждый дополнительный год обучения), то перед кризисом 2008-2009 гг. их рост полностью прекратился, а после его окончания так и не возобновился [Тихонова 2017; Тихонова, Каравай 2018].

Еще одним способом снижения рисков бедности и малообеспеченности для профессионалов, как и для представителей других профессиональных групп, является отказ от рождения детей или, по крайней мере, от рождения второго и последующих детей. Учитывая все еще сохраняющуюся значимость детей в российской культуре, это обычно психологически тяжелый для самого человека и являющийся нежелательным в масштабах государства путь предотвращения бедности и малообеспеченности. Однако часть профессионалов выбирает и его, поскольку среднее число детей до 16 лет в домохозяйствах данной профессиональной группы составляет 0,68 при 0,74 у квалифицированных рабочих или специалистов средней квалификации, 0,71 у рядовых работников торговли и 0,71 по работающему населению страны в целом.

Наконец, еще одним доступным профессионалам способом повышения их доходов выступает смена места работы в рамках их нынешнего места жительства. Как свидетельствуют данные РМЭЗ, наименьшую удовлетворенность вызывает новая работа и оплата труда на ней у сменивших сразу и место работы, и специальность. Видимо, такая мера является сейчас для профессионалов в значительной степени вынужденной и обеспечивает скорее сохранение занятости, чем улучшение ее качества или повышение зарплаты. Наибольший же эффект в плане не только роста их общей удовлетворенности своей работой или оплатой труда на ней, но и реального размера зарплаты приносит профессионалам смена места работы при сохранении своей профессии: в конце 2019 г. средняя зарплата составляла в данной группе 46150 руб. при 34136 руб. в группе работающих на старой работе. Однако показатели человеческого капитала в группе сменивших место занятости при сохранении старой профессии были самыми низкими из всех подгрупп профессионалов, менявших работу. Это в очередной раз свидетельствует о том, что сейчас в России отнюдь не качество человеческого капитала позволяет обычно представителям данной группы трудоустраиваться на более привлекательные рабочие места. 


\section{Выводы}

Бедность и малообеспеченность распространены среди российских профессионалов довольно широко, хотя и меньше, чем в других профессиональных группах. Профессионалы - очень многочисленная группа, но еще до начала вызванного пандемией кризиса почти миллион человек из их числа жили на доходы ниже прожиточного минимума. При всей масштабности этой цифры, в сравнении с 2000 г., когда за чертой бедности находилось больше половины профессионалов, такая ситуация выглядит намного более благополучной. Однако позитивные сдвиги в данной области произошли в основном еще до начала кризиса 2008-2009 гг., в то время как в 2010-х гг. бедность среди профессионалов сокращалась даже более медленными темпами, чем, например, у неквалифицированных рабочих.

Ключевой причиной бедности и малообеспеченности профессионалов является недооценка высококвалифицированного нефизического труда в России. Стоимость инвестиций в формирование качественного человеческого капитала при определении их зарплат обычно учитывается в явно недостаточном объеме, а цену на труд профессионалов в большей степени определяет соотношение спроса и предложения на конкретных сегментах локальных рынков труда, чем осуществленные инвестиции. Кроме того, на занижении зарплат профессионалов сказываются следующие факторы: унаследованная от СССР слабая дифференциация оплаты труда массовых профессиональных групп; сформировавшееся в российской культуре в силу бесплатности образования в тот период, а отчасти и сегодня, непонимание необходимости рент на него; слабая конкурентность российской экономики, детерминирующая по меньшей мере такую же значимость ресурса социальных сетей при подборе персонала, как и качества человеческого капитала. С учетом всего этого не удивительно, что и оплата их труда, и среднедушевые доходы в их семьях, и обусловленные этим доли бедных и малообеспеченных в составе данной группы мало отличаются от ситуации в группах с гораздо менее качественным человеческим капиталом.

Общую недооценку высококвалифицированного нефизического труда в российской экономике усугубляют разного рода исторически сложившиеся неравенства оплаты труда: региональные, поселенческие, меж- и внутриотраслевые, неравенства в оплате труда в разных секторах экономики, на предприятиях различного размера и т. п. Ключевую роль среди них играют поселенческие неравенства, поскольку с учетом специфики структуры экономики разных типов поселений все эти неравенства накладываются в них друг на друга, формируя мощный кумулятивный эффект. В итоге, если благополучные профессионалы в своей массе сосредоточены в крупных городах, то бедные - в малых поселениях, прежде всего сельских, и тенденция все большей их концентрации именно в этом типе поселений прослеживается за последние 20 лет совершенно отчетливо.

К причинам бедности профессионалов, имеющим макроэкономический характер, добавляются и усугубляющие их действие причины микроуровня, в т. ч. специфика человеческого капитала профессионалов из разных типов поселений. Однако для большинства профессионалов роль этого фактора не является решающей 
и с годами скорее уменьшается, чем увеличивается. Еще одна группа причин бедности профессионалов, также относящаяся к микроуровню, - это причины, связанные с размером и структурой их домохозяйств. Роль этой группы причин их бедности в последние годы, несмотря на меры господдержки, не уменьшилась, и ключевую роль среди них играет нагрузка несовершеннолетними детьми. При этом бедность профессионалов в большей степени, чем малообеспеченность, связана с позициями на рынке труда, обусловленными спецификой человеческого капитала, в то время как для малообеспеченности относительно важнее факторы социально-демографического характера.

Набор способов изменить свое положение за счет собственных усилий для профессионалов невелик. Это, во-первых, отказ от рождения детей - способ среди профессионалов пока не слишком популярный, хотя и встречающийся. Во-вторых, это возможность наращивать качество своего человеческого капитала. Однако в любом типе поселений большинство имеющих качественный человеческий капитал профессионалов имеют в лучшем случае средние по размеру зарплаты, не способные обеспечить без высоких рисков бедности и малообеспеченности даже простое демографическое воспроизводство, что свидетельствует о бесперспективности такого способа борьбы с соответствующими рисками для большинства профессионалов. В-третьих, это переезд в другой тип поселений. Популярность этого способа улучшения своего положения среди профессионалов с годами падает, прежде всего потому, что те из них, кто объективно должен быть в наибольшей степени заинтересован в таком переезде, не имеют необходимых для этого ресурсов. Кроме того, поскольку они чаще обладают человеческим капиталом относительно худшего качества, то такого рода переезд для многих из них может оказаться и экономически малоэффективным. В-четвертых, это вторичная занятость, распространенность которой за последние 20 лет среди профессионалов сократилась, а смысл изменился. И раньше, и сейчас доступ к ней имели наиболее квалифицированные представители данной профессиональной группы, но если в 2011 г. они устраивались на дополнительную работу, чтобы улучшить свое материальное положение по отношению к остальным, то в 2019 г. вторичную занятость имели уже обычно лишь те из них, чья зарплата была заметно ниже, чем средняя для профессионалов, а результатом все больших дополнительных нагрузок имеющих ее оказывалась лишь возможность сохранить соответствующий профессионалам в целом профиль доходного распределения. Наконец, в-пятых, это смена места работы в рамках нынешнего места жительства, которая сейчас зачастую становится способом сохранения занятости, а не улучшения ее качества, и исключением является лишь переход на новую работу при сохранении старой специальности, который способствует росту зарплаты в среднем примерно на 20\%. Однако качество человеческого капитала не является решающим фактором для нахождения более привлекательной и лучше оплачиваемой работы.

Подводя итоги, можно сказать, что проблема бедности и малообеспеченности среди профессионалов в России сохраняет свою актуальность. Сложившееся положение чревато серьезными последствиями для российского общества в целом и требует от него активных действий. Высокие риски бедности при наличии двух детей порождают проблемы с воспроизводством высококачественной рабочей силы в масштабах страны. Слабая связь качества человеческого капитала и уровня заработной платы демотивирует профессионалов в наращивании их знаний и навы- 
ков. Большое количество и важная роль для заработных плат профессионалов факторов, связанных со структурой экономики в определенной локации, принижают роль их собственных усилий для повышения своего благосостояния и т. д. Все это требует активизации государственной социально-экономической политики даже в отношении этой, казалось бы, относительно благополучной на общем фоне населения страны группы.

\section{Список источников}

Белл Д. (1999) Грядущее постиндустриальное общество. Опыт социального прогнозирования. М.: Academia.

Вишневская Н.Т. (ред.) (2017) Профессии на российском рынке труда. М.: ВШЭ.

Гелбрейт Дж. (1969) Новое индустриальное общество. М.: Прогресс.

Гимпельсон В.Е., Капелюшников Р.И. (ред.) (2011) Российский работник: образование, профессия, квалификация. М.: ВШЭ.

Голенков 3.Т. (ред.) (2015) Наемный работник в современной России. М.: Новый хронограф.

Горшков М.К., Тихонова Н.Е. (ред.) (2014) Бедность и бедные в современной России. М.: Весь мир.

Заславская Т.И. (1996) Трансформация социальной структуры российского общества // Материалы международного симпозиума «Куда идет Россия?.. Социальная трансформация постсоветского пространства». М.: Аспект-пресс.

Карабчук Т.С., Пашинова Т.Р., Соболева Н.Э. (2013) Бедность домохозяйств в России: что говорят данные РМЭЗ ВШЭ// Мир России. Т. 22. № 1. С. 155-175.

Кастельс М. (2000) Информационная эпоха: экономика, общество и культура. М.: ВШЭ.

Латова Н.В. (2021) Миграционные установки и предпочтения российских специалистов в контексте концепции человеческого капитала // Мониторинг общественного мнения: экономические и социальные перемены. № 4. С. 429-450. DOI: $10.14515 /$ monitoring.2021.4.1692

Лукьянова А.Л. (2010) Отдача от образования: что показывает мета-анализ // Экономический журнал Высшей школы экономики. Т. 14. № 3. С. 326-348.

Любимова Т.С., Шкаратан О.И., Инясевский С.А. (2008) Новый средний класс и информациональные работники на российском рынке труда // Общественные науки и современность. № 1. С. 5-27.

Мансуров В.А. (ред.) (2013) Профессионалы в эпоху реформ: динамика идеологии, статуса и ценностей. М.: ИС РАН, РОС.

Мансуров В.А., Юрченко О.В. (2013) Социология профессиональных групп в России: история становления и перспективы // Вестник Института социологии. Т. 4. № 2. C. $91-106$.

Овчарова Л.Н. (2012) Теоретико-методологические вопросы определения и измерения бедности // SPERO. Социальная политика: экспертиза, рекомендации, обзоры. № 16. С. 15-38.

Овчарова Л.Н., Попова Д.О., Пишняк А.И., Зубаревич Н.В., Горина Е.А., Бирюкова С.С., Нагерняк М.А., Калабихина И.Е., Ковалевский А.Р. (2011) Анализ положения детей в Российской Федерации: на пути к обществу равных возможностей. М.: Детский фонд ООН - ЮНИСЕФ.

Пишняк А.И., Попова Д.О. (2011) Бедность и благосостояние российских семей с детьми на разных этапах экономического цикла // SPERO. Социальная политика: экспертиза, рекомендации, обзоры. № 14. С. 57-78.

Рабочая сила, занятость и безработица в России (по результатам выборочных обследований рабочей силы) (2018). Статистический сборник. М.: Росстат.

Радаев В.В. (2000) Забытые властью: портрет новых бедных // Заславская Т.И. (ред.) Куда идет Россия. Власть, общество, личность. М.: МВШСЭН. С. 328-340. 
Слободенюк Е.Д. (2013) Нерыночные факторы бедности в современной России и пути совершенствования социальной политики // Журнал исследований социальной политики. Т. 11. № 3. С. 391-406.

Тихонова Н.Е. (2003) Феномен городской бедности в современной России. М.: Летний сад.

Тихонова Н.Е. (2013) Бедность в современной России: ключевые проблемы // Мау В., Клячко М. (ред.) Развитие человеческого капитала - новая социальная политика: сборник научных статей. М.: Дело. С. 297-317.

Тихонова Н.Е. (2017) Человеческий капитал профессионалов и руководителей: состояние и динамика // Вестник Института социологии. Т. 8. № 2. С. 140-165. DOI: $10.19181 /$ vis.2017.21.2.462

Тихонова Н.Е. (ред.) (2018) Модель доходной стратификации российского общества: динамика, факторы, межстрановые сравнения. М.; СПб.: Нестор-История.

Тихонова Н.Е. (2020а) Специалисты в современной России: социально-демографические особенности состава и ключевые проблемы // Социологический журнал. Т. 26. № 3. C. 64-89. DOI: 10.19181/socjour.2020.26.3.7396

Тихонова Н.Е. (2020b) Российские профессионалы: специфика рабочих мест и человеческого потенциала // Социологические исследования. №. 10. С. 71-81. DOI: $10.31857 / \mathrm{S} 013216250010300-3$

Тихонова Н.Е., Каравай А.В. (2017) Человеческий капитал российских рабочих: общее состояние и специфические особенности // Мир России. Т. 26. № 3. С. 6-35. DOI: $10.17323 / 10.17323 / 1811-038 X-2017-26-3-6-35$

Тихонова Н.Е., Каравай А.В. (2018) Динамика некоторых показателей общего человеческого капитала россиян в 2010-2015 гг. // Социологические исследования. № 5. С. 84-98. DOI: $10.7868 / \mathrm{S} 0132162518050082$

Тощенко Ж.Т. (2018) Прекариат: от протокласса к новому классу. М.: Наука.

Труд и занятость в России (2019). Статистический сборник. М.: Росстат.

ФСГС РФ (2020). Сведения о заработной плате работников организаций по категориям персонала и профессиональным группам работников за октябрь 2019 г. (статистический бюллетень) // https:/gks.ru/compendium/document/60671, дата обращения 02.08.2020.

Чернина Н.В. (1994) Бедность как социальный феномен российского общества // Социологические исследования. № 3. С. 54-61.

Ярошенко С.С. (2010) «Новая бедность» в России после социализма // Laboratorium: Журнал социальных исследований. № 2. С. 221-251.

Becker G.S. (1964) Human Capital: A Theoretical and Empirical Analysis with Special Reference to Education, University of Chicago Press.

Cedefop (2012). Future Skills Supply and Demand in Europe. Forecast 2012. Cedefop Research Paper. No. 26, Luxembourg: Publications Office of the European Union.

Crouch C. (2010) Occupational Structure and Social Models in European Societies: Working Paper, University of Warwick Business School. August.

International Standard Classification of Occupations: ISCO-08. Structure, Group Definitions and Correspondence Tables (2012), Geneva: ILO.

Macdonald K.M. (1995) The Sociology of the Professions, London; Thousand Oaks, Calif.: Sage.

Svensson L.G., Evetts J. (eds.) (2010) Sociology of Professions: Continental and Anglo-Saxon Traditions, Daidalos.

Townsend P. (1979) Poverty in the United Kingdom: A Survey of Household Resources and Standards of Living, Berkeley: University of California Press. 


\title{
N.E. TIKHONOVA*, E.D. SLOBODENYUK**
}

\begin{abstract}
*Natalia E. Tikhonova - DSc in Sociology, Professor-researcher, HSE University; Chief Researcher, Federal Center of Theoretical and Applied Sociology of the Russian Academy of Sciences, Moscow, Russian Federation, ntihonova@hse.ru, https://orcid.org/0000-0002-5826-4418

**Ekaterina D. Slobodenyuk - PhD in Sociology, Research Fellow, HSE University; Senior Research Fellow, Federal Center of Theoretical and Applied Sociology of the Russian Academy of Sciences, Moscow, Russian Federation, eslobodenyuk@hse.ru, https://orcid.org/0000-0002-4255-5050
\end{abstract}

Citation: Tikhonova N.E., Slobodenyuk E.D. (2022) Poverty among Russian Professionals: Scale, Causes, Trends. Mir Rossii, vol. 31, no 1, pp. 113-137 (in Russian). DOI: 10.17323/1811-038X-2022-31-1-113-137

\begin{abstract}
Poverty among Russian professionals is widespread: at the end of 2019, almost a million people were affected. Its reduction, in comparison with the 1990s, occurred mainly in the mid-2000s, while since the 2010s the rate of reduction was slower than among other occupational groups. Poverty among professionals has several causes. These have to do with territorial, sectoral, regional, and other inequalities. The role of these inequalities has grown, although territorial inequalities play the leading role. Demographic factors, i.e., the size and the nature of dependency burden, especially young children, are also at play. The earnings of a significant fraction of professionals do not enable even to have 1-2 children without significant risks of poverty. Despite state aid to families with children, the significance of household size for poverty risks has not diminished. The risk of poverty among professionals also varies according to the quality of their human capital. Highly skilled professionals have a significantly lower risk of poverty than do lower-skilled professionals. Nevertheless, poverty among professionals in Russia is generally caused by a severe underestimation of their human capital. Individual solutions to escape poverty (i.e., migration, job change, secondary employment, and human capital investment) are currently deemed ineffective, even though some professionals still employ these strategies to a greater or lesser extent.
\end{abstract}

Keywords: social structure, occupational structure, professionals, poverty, low income, human capital, secondary employment

\section{References}

Becker G.S. (1964) Human Capital: A Theoretical and Empirical Analysis with Special Reference to Education, University of Chicago Press.

Bell D. (1999) The Coming of Post-Industrial Society. Social Forecasting Experience, Moscow: Academia (in Russian).

This research was supported by the Russian Foundation for Basic Research, grant № 19-29-07172).

The article was received in October 2020. 
Castells M. (2000) Information Age: Economy, Society and Culture, Moscow: HSE (in Russian). Cedefop (2012). Future Skills Supply and Demand in Europe. Forecast 2012. Cedefop Research Paper. No. 26, Luxembourg: Publications Office of the European Union.

Chernina N.V. (1994) Poverty as a Social Phenomenon in Russian Society. Sociological Studies, no 3, pp. 54-61 (in Russian).

Crouch C. (2010) Occupational Structure and Social Models in European Societies: Working Paper, University of Warwick Business School. August.

FSSS of the Russian Federation (2020). Information on the Salaries of Employees of Organizations by Categories of Personnel and Professional Groups of Employees for October 2019 (Statistical Bulletin). Available at: https://gks.ru/compendium/document/60671, accessed 02.08.2020 (in Russian).

Galbraith J. (1969) The New Industrial State, Moscow: Progress (in Russian).

Gimpelson V.E., Kapeliushnikov R.I. (eds.) (2011) Russian Worker: Education, Profession, Qualifications, Moscow: HSE (in Russian).

Golenkov Z.T. (ed.) (2015) Employee in Contemporary Russia, Moscow: Novyj Khronograf (in Russian).

Gorshkov M.K., Tikhonova N.E. (eds.) (2014) Poverty and the Poor in Contemporary Russia, Moscow: Ves' mir (in Russian).

International Standard Classification of Occupations: ISCO-08. Structure, Group Definitions and Correspondence Tables (2012), Geneva: ILO.

Karabchuk T.S., Pashinova T.R., Soboleva N.E. (2013) Poverty of Russian Households: What We Know About It from RLMS Database. Mir Rossii, vol. 22, no 1, pp. 155-175 (in Russian).

Labor and Employment in Russia (2019). Statistical Collection. Moscow: Rosstat (in Russian).

Labor Force, Employment and Unemployment in Russia (Based on the Results of Sample Labor Force Surveys) (2018). Statistical Collection, Moscow: Rosstat (in Russian).

Latova N.V. (2021) Migration Attitudes and Preferences of Russian Specialists in the Context of the Human Capital Concept. Monitoring of Public Opinion: Economic and Social Changes, no 4, pp. 429-450 (in Russian). DOI: 10.14515/monitoring.2021.4.1692

Lukyanova A.L. (2010) Returns to Education in Russia: Evidence from Meta-Analysis. The HSE Economic Journal, vol. 14, no 3, pp. 326-348 (in Russian).

Lyubimova T.S., Shkaratan O.I., Inyasevsky S.A. (2008) New Middle Class and Information Workers in the Russian Labor Market. Social Sciences and Contemporary World, no 1, pp. 5-27 (in Russian).

Macdonald K.M. (1995) The Sociology of the Professions, London; Thousand Oaks, Calif.: Sage. Mansurov V.A. (ed.) (2013) Professionals in the Era of Reforms: Dynamics of Ideology, Status and Values, Moscow: IS RAS, ROS (in Russian).

Mansurov V.A., Yurchenko O.V. (2013) Sociology of Professional Groups: History and Prospects. Bulletin of the Institute of Sociology, vol. 4, no 2, pp. 9-106 (in Russian).

Ovcharova L.N. (2012) Theoretical and Methodological Issues of Defining and Measuring Poverty. SPERO, no 16, pp. 15-38 (in Russian).

Ovcharova L.N., Popova D.O., Pishnyak A.I., Zubarevich N.V., Gorina E.A., Biryukova S.S., Nagernyak M.A., Kalabikhina I.E., Kovalevsky A.R. (2011) Analysis of the Situation of Children in the Russian Federation: on the Way to a Society of Equal Opportunities, Moscow: UN Children's Fund - UNICEF (in Russian).

Pishnyak A.I., Popova D.O. (2011) Poverty and Well-being of Russian Households with Children at Different Stages of the Economic Cycle. SPERO, no 14, pp. 57-78 (in Russian).

Radaev V.V. (2000) Forgotten by the Government: A Portrait of the New Poor. Where Russia Is Going. Power, Society, Personality (ed. Zaslavskaya T.I.), Moscow: MVSHSEN, pp. 328-340 (in Russian).

Slobodenyuk E.D. (2013) Non-Market Factors of Poverty in Modern Russia and Ways to Improve Social Policy. Journal of Social Policy Research, vol. 11, no 3, pp. 391-406 (in Russian).

Svensson L.G., Evetts J. (eds.) (2010) Sociology of Professions: Continental and Anglo-Saxon Traditions, Daidalos.

Tikhonova N.E. (2003) The Phenomenon of Urban Poverty in Contemporary Russia, Moscow: Letnij Sad (in Russian). 
Tikhonova N.E. (2013) Poverty in Contemporary Russia: Key Issues. Human Capital Development - New Social Policy: Collection of Scientific Articles (eds. Mau V., Klyachko M.), Moscow: Delo, pp. 297-317 (in Russian).

Tikhonova N.E. (2017) Human Capital of Professionals and Managers: The Condition and Dynamic. The Bulletin of the Institute of Sociology, vol. 8, no 2, pp. 140-165 (in Russian). DOI: 10.19181/vis.2017.21.2.462

Tikhonova N.E. (ed.) (2018) The Model of Income Stratification of Russian Society: Dynamics, Factors, Cross-Country Comparisons, Moscow; Saint Petersburg: Nestor-History (in Russian).

Tikhonova N.E. (2020a) Specialists in Modern Russia: Socio-Demographic Composition and Key Problems. Sociological Journal, vol. 26, no 3, pp. 64-89 (in Russian). DOI: $10.19181 /$ socjour.2020.26.3.7396

Tikhonova N.E. (2020b) Russian Professionals: Specifics of Jobs and of Human Potential. Sociological Studies, no 10, pp. 71-81 (in Russian). DOI: 10.31857/S013216250010300-3

Tikhonova N.E., Karavai A.V. (2017) The Human Capital of Russian Workers: The Overall State and Its Specifics. Mir Rossii, vol. 26, no 3, pp. 6-35 (in Russian). DOI: 10.17323/10.17323/1811-038X-2017-26-3-6-35

Tikhonova N.E., Karavai A.V. (2018) Dynamics of Some Indicators of Russians' General Human Capital in 2010-2015. Sociological Studies, no 5, pp. 84-98 (in Russian). DOI: $10.7868 / \mathrm{S} 0132162518050082$

Toshchenko J.T. (2018) Precariat. From Protoclass to New Class, Moscow: Nauka (in Russian).

Townsend P. (1979) Poverty in the United Kingdom: A Survey of Household Resources and Standards of Living, Berkeley: University of California Press.

Vishnevskaya N.T. (ed.) (2017) Professions on the Russian Labor Market, Moscow: HSE (in Russian).

Yaroshenko S.S. (2010) "New Poverty” in Russia after Socialism. Laboratory, no 2, pp. 221-251 (in Russian).

Zaslavskaya T.I. (1996) Transformation of the Social Structure of Russian Society. Proceedings of the International Symposium "Where Is Russia Going? Social Transformation of the post-Soviet Space”, Moscow: Aspect-press (in Russian). 